\title{
Investigating relationships between aerosol optical depth and cloud fraction using satellite, aerosol reanalysis and general circulation model data
}

\author{
B. S. Grandey ${ }^{1, *}$, P. Stier ${ }^{1}$, and T. M. Wagner ${ }^{1}$ \\ ${ }^{1}$ Atmospheric, Oceanic and Planetary Physics, Department of Physics, University of Oxford, UK \\ * now at: Singapore-MIT Alliance for Research and Technology, Singapore, Singapore
}

Correspondence to: B. S. Grandey (benjamin@smart.mit.edu)

Received: 12 November 2012 - Published in Atmos. Chem. Phys. Discuss.: 29 November 2012

Revised: 7 March 2013 - Accepted: 7 March 2013 - Published: 18 March 2013

\begin{abstract}
Strong positive relationships between cloud fraction $\left(f_{\mathrm{c}}\right)$ and aerosol optical depth $(\tau)$ have been reported. Data retrieved from the MODerate resolution Imaging Spectroradiometer (MODIS) instrument show positive $f_{\mathrm{c}}-\tau$ relationships across most of the globe. A global mean $f_{\mathrm{c}}$ increase of approximately 0.2 between low and high $\tau$ conditions is found for both ocean and land. However, these relationships are not necessarily due to cloud-aerosol interactions. Using state-of-the-art Monitoring Atmospheric Composition and Climate (MACC) reanalysis-forecast $\tau$ data, which should be less affected by retrieval artefacts, it is demonstrated that a large part of the observed $f_{\mathrm{c}}-\tau$ signal may be due to cloud contamination of satellite-retrieved $\tau$. For longer MACC forecast time steps of $24 \mathrm{~h}$, which likely contain less cloud contamination, some negative $f_{\mathrm{c}}-\tau$ relationships are found. The global mean $f_{\mathrm{c}}$ increase between low and high $\tau$ conditions is reduced to 0.1 , suggesting that cloud contamination may account for approximately one half of the satelliteretrieved increase in $f_{\mathrm{c}}$. ECHAM5-HAM general circulation model (GCM) simulations further demonstrate that positive $f_{\mathrm{c}}-\tau$ relationships may arise due to covariation with relative humidity. Widespread negative simulated $f_{\mathrm{c}}-\tau$ relationships in the tropics are shown to arise due to scavenging of aerosol by convective precipitation. Wet scavenging events are likely poorly sampled in satellite-retrieved data, because the properties of aerosol below clouds cannot be retrieved. Quantifying the role of wet scavenging, and assessing GCM representations of this important process, remains a challenge for future observational studies of aerosol-cloud-precipitation interactions.
\end{abstract}

\section{Introduction}

Microphysical and dynamical interactions between aerosols and clouds are associated with some of the largest uncertainties in projections of future climate (Lohmann and Feichter, 2005; Forster et al., 2007). One proposed aerosol effect on clouds is the cloud lifetime effect (Albrecht, 1989): increasing aerosol concentrations may decrease cloud droplet size, suppressing precipitation and enhancing the retention of liquid water by the cloud, hence increasing the lifetime of the cloud and the total cloud fractional cover. Positive relationships between satellite-retrieved cloud fraction $\left(f_{\mathrm{c}}\right)$ and aerosol optical depth $(\tau)$ have been reported and have been interpreted to indicate aerosol cloud lifetime effects (e.g. Koren et al., 2005; Kaufman et al., 2005; Yuan et al., 2011). However, these $f_{\mathrm{c}}-\tau$ relationships may not be due to aerosol effects on clouds. Many possible reasons for observed relationships between aerosol and cloud properties exist. Expanding on Quaas et al. (2010), of particular relevance to the $f_{\mathrm{c}}-\tau$ relationships are the following potential mechanisms:

1. Climatological spatial gradient effects may lead to spurious $f_{\mathrm{c}}-\tau$ relationships if data are analysed on large regional scales larger than $4^{\circ} \times 4^{\circ}$ (Grandey and Stier, 2010).

2. Satellite data errors may lead to positive $f_{\mathrm{c}}-\tau$ relationships. Pixels in thin and broken cloud fields, with high $f_{\mathrm{c}}$, may be mistakenly flagged as cloud-free when they are contaminated by cloud, leading to erroneously high $\tau$ retrievals (Huang et al., 2011). Furthermore, three-dimensional scattering of light by inhomogeneous 
clouds may also lead to erroneously high $\tau$ retrievals (Várnai and Marshak, 2009). A possible way to avoid these problems may be to combine satellite-retrieved $f_{\mathrm{c}}$ data with simulated $\tau$ data. For example, Koren et al. (2010) combine chemical transport model $\tau$ data with MODerate resolution Imaging Spectroradiometer (MODIS) cloud data when investigating deep convective clouds over the Atlantic Ocean. General circulation model (GCM) data should not suffer from this problem.

3. The simple aerosol cloud lifetime effect conceptual model would predict positive $f_{\mathrm{c}}-\tau$ relationships (Albrecht, 1989), assuming $\tau$ is a suitable surrogate for cloud condensation nuclei concentration $(\mathrm{CCN}$; Andreae, 2009). Many GCMs attempt to simulate this effect by coupling aerosol to the autoconversion scheme in stratiform cloud microphysics schemes, an effect that can often be switched on or off, although a large model error may exist. However, increasing aerosol concentrations also have the potential to decrease cloud fractional cover, for example via the semi-direct effect (Ackerman et al., 2000).

4. Relative humidity may drive positive $f_{\mathrm{c}}-\tau$ relationships (Quaas et al., 2010; Chand et al., 2012). Cloud fraction generally increases with relative humidity. Aerosols swell hygroscopically in high relative humidity conditions, increasing $\tau$. GCMs should be able to reproduce this effect, particularly as cloud cover parameterizations are generally heavily dependent on relative humidity (e.g. Sundqvist et al., 1989), although there may be significant model errors. GCM-modelled dry $\tau$, which assumes no hygroscopic aerosol growth and may therefore be a better surrogate for the CCN which would be activated at a given supersaturation, allows for this relative humidity effect to be accounted for, as demonstrated by Quaas et al. (2010). Chand et al. (2012) have recently used a Gaussian probability density function model to show that observed $f_{\mathrm{c}}-\tau$ relationships are consistent with hygroscopic growth of aerosol.

5. Other meteorological factors may lead to spurious $f_{\mathrm{c}}-\tau$ relationships. For example, $10 \mathrm{~m}$ wind speed is capable of explaining a significant part of observed $f_{\mathrm{c}}-\tau$ relationships over ocean (Engström and Ekman, 2010). This is because $\tau$ increases with $10 \mathrm{~m}$ wind speed over ocean likely due to both sea-surface brightness contamination of the $\tau$ retrieval and genuine wind speed dependent emission of sea salt (Grandey et al., 2011), and higher $f_{\mathrm{c}}$ values are likely found for meteorological conditions associated with higher wind speeds. GCMs should be capable of reproducing meteorological effects.

6. Wet scavenging of aerosols by precipitation might lead to negative $f_{\mathrm{c}}-\tau$ relationships, assuming a positive correlation between $f_{\mathrm{c}}$ and precipitation. GCM aerosol modules simulate wet scavenging as the major removal mechanism for atmospheric aerosol.

7. Cloud processing of aerosols may alter the optical properties of aerosols. Far away from sources, aerosol particles may have been cycled through clouds approximately three times (Pruppacher and Jaenicke, 1995). Aerosol which has been recently cycled through a cloud may be more hydrated than aerosol further away, potentially leading to an increase in $\tau$ in the immediate vicinity of clouds (Koren et al., 2007). (It is worth noting that this effect, whereby clouds may affect aerosol properties, is different from the larger scale relative humidity effect, discussed in the fourth point above, whereby relative humidity variations drive cloud formation.)

In order to investigate some of these possible mechanisms, two tools are used in this paper alongside AquaMODIS data. Firstly, Monitoring Atmospheric Composition and Climate (MACC) project reanalysis-forecast $\tau$ data are used in an attempt to investigate cloud contamination errors in the MODIS $\tau$ data (second point above). Secondly, the ECHAM5-HAM GCM is used to investigate the cloud lifetime effect, relative humidity and wet scavenging contributions (third, fourth and sixth points above). Spatial gradient effects (first point above) have been investigated elsewhere and are accounted for in the methodology used in this paper (Grandey and Stier, 2010). As discussed in the seventh point above, cloud processing effects are unlikely to significantly contribute to $f_{\mathrm{c}}-\tau$ relationships or scales larger than a few kilometres, so cloud processing is not investigated here. Apart from relative humidity, other meteorological factors (fifth point above) are outside the scope of the current paper, remaining an important topic for further research.

The following questions are asked in this paper: to what extent may cloud contamination errors be responsible for the observed $f_{\mathrm{c}}-\tau$ relationships? What are the dominant physical processes leading to genuine $f_{\mathrm{c}}-\tau$ relationships?

\section{Method}

The satellite data used in this paper are from the official Aqua-MODIS science team Collection 5 level 3 daily $1^{\circ} \times 1^{\circ}$ cloud and aerosol dataset (MYD08_D3) (Platnick et al., 2003; Remer et al., 2005). Total cloud fraction $\left(f_{\mathrm{c}}\right)$ and aerosol optical depth at $550 \mathrm{~nm}(\tau)$ are of interest here.

As mentioned above, cloud contamination of $\tau$ retrievals may cause spurious $f_{\mathrm{c}}-\tau$ relationships, something that may be avoidable by pairing satellite-derived $f_{\mathrm{c}}$ with $\tau$ from a state-of-the-art reanalysis-forecast aerosol dataset. However, residual cloud contamination may remain, and model errors may be introduced. The reanalysis-forecast $\tau$ data used in this paper are from the MACC project (Morcrette et al., 2011). The model uses a mixed bulk and bin aerosol scheme (Morcrette et al., 2009). MODIS Collection $5 \tau$ data are 
assimilated using a 4D-Var scheme with a $12 \mathrm{~h}$ assimilation window (Benedetti et al., 2009). The MACC data are designed to be unbiased with respect to MODIS $\tau$ data (Morcrette et al., 2011). Further discussion of the MACC data, including comparisons with satellite-retrieved and AErosol RObotic NETwork (AERONET) aerosol data, is provided in Morcrette et al. (2011). MACC data from two different forecast time steps, relative to the most recent assimilation time of 00:00 UTC, are used: $t+3 \mathrm{~h} ; t+24 \mathrm{~h}$ from assimilation the previous day. The $t+24 \mathrm{~h} \tau$ is likely to have less residual cloud contamination but more model bias than the $t+3 \mathrm{~h}$ $\tau$. Since the MACC $\tau$ data approximately correspond to the start of each day, they are temporally interpolated equally between each pair of days, corresponding to interpolation times of 15:00 UTC for $t+3 \mathrm{~h}$ and 12:00 UTC for $t+24 \mathrm{~h}$. It is assumed that the interpolated $\tau$ is representative of the $\tau$ at the Aqua daytime equatorial overpass time of 13:30 LT. The MACC data are spatially interpolated from $1.125^{\circ} \times 1.125^{\circ}$ to $1^{\circ} \times 1^{\circ}$ in order to match the MODIS data. The MODIS and MACC data used in this paper cover 2003-2007.

Data from the ECHAM5 GCM with the HAM aerosol model are also used (Stier et al., 2005; Zhang et al., 2012). The HAM aerosol model has been coupled to the twomoment cloud microphysics via activation of cloud droplets, droplet number dependent autoconversion and the impact of the effective radius on the cloud radiative properties, allowing the cloud albedo and cloud lifetime aerosol effects to be represented (Lohmann et al., 2007; Stier et al., 2013). Of particular interest here is the cloud lifetime effect on $f_{c}$. Six simulations are performed. Three of these use the Sundqvist cloud cover scheme, which parameterizes $f_{\mathrm{c}}$ using relative humidity as the only input (Sundqvist et al., 1989); three use the statistical Tompkins cloud cover scheme, which uses a prognostic probability density function of water vapour, considering processes such as convection, turbulence and microphysics (Tompkins, 2002). For each cloud cover scheme, three simulations are conducted: a control run, with aerosol indirect effects represented; a NoAIE run, with no aerosol indirect effects (fixed cloud droplet number concentration); and a NoConvScav run, with aerosol indirect effects represented but with no convective wet scavenging of aerosols. Only the results for the Sundqvist simulations are presented in the main body of this paper. The results for the Tompkins simulations, which are very similar to those for the Sundqvist simulations, can be viewed in the Supplement. As in Zhang et al. (2012), all simulations use year 2000 present-day aerosol and precursor emissions, are nudged to year 2000 meteorology using European Centre for Medium-Range Weather Forecasts reanalysis (ERA-40) data, and are preceded by a three-month spin-up period from October 1999. All simulations are run at T63 horizontal resolution, corresponding to $1.875^{\circ} \times 1.875^{\circ}$, and L31 vertical resolution. Aerosol and cloud data are output at $6 \mathrm{~h}$ resolution. The $f_{\mathrm{c}}$ data are calculated assuming maximum-random overlap of cloud layers, using an updated version of the satellite simulator module used in Quaas et al. (2009) (Stier et al., 2013). In addition to $\tau$ from all simulations, dry $\tau$ output from the control simulations is also used. Following Quaas et al. (2010), dry $\tau$ is diagnosed by reducing the extinction coefficient of each aerosol mode by the volume fraction of water for that mode, approximating the $\tau$ that would be calculated if there was no hygroscopic swelling of the aerosols.

The $f_{\mathrm{c}}$ data are categorized into two cases: low $\tau$ conditions, where $\tau$ is less than the median for that grid box, season and dataset; high $\tau$ conditions, where $\tau$ is greater than the median. The mean $f_{\mathrm{c}}$ for each grid box, season and dataset is then calculated for low $\tau$ and high $\tau$ conditions, before averaging across all four seasons to produce annual mean fields. The difference in $f_{\mathrm{c}}$ between low and high conditions is then calculated. The analysis is limited to $60^{\circ} \mathrm{S}-60^{\circ} \mathrm{N}$.

\section{Results and discussion}

Figure 1 shows the difference in $f_{\mathrm{c}}$ between low and high $\tau$ conditions. Positive $f_{\mathrm{c}}-\tau$ relationships, shown in red, are found globally. For more than $99 \%$ of the grid boxes with data, the difference is greater than the standard error for that grid box. Positive $f_{\mathrm{c}}-\tau$ relationships have been observed in other studies, such as those by Koren et al. (2005) and Kaufman et al. (2005) who investigated clouds over the North Atlantic Ocean using earlier MODIS data. Particularly strong relationships, shown in darker shades of red, are found over the subtropical oceans, southern South America and eastern North America. The relationship over the extratropical southern oceans is weaker. Over ocean, there is a mean increase in $f_{\mathrm{c}}$ of 0.20 from 0.51 to 0.71 ; over land, there is also a mean increase of 0.20 from 0.30 to 0.50 .

An increase of 0.2 in $f_{\mathrm{c}}$ is relatively large. For example, assuming an idealised ocean albedo of 0.1 and a cloud albedo of 0.5 , a 0.2 increase in $f_{\mathrm{c}}$ may lead to an albedo increase of order 0.1 over ocean. Given a solar constant of $1370 \mathrm{~W} \mathrm{~m}^{-2}$, averaged to $340 \mathrm{~W} \mathrm{~m}^{-2}$ across the surface of the earth, an albedo increase of 0.1 would correspond to an upwelling shortwave radiation increase of order $30 \mathrm{Wm}^{-2}$ at the top of the atmosphere. Of course, this shortwave increase might be offset be a sizeable longwave decrease, particularly if the cover of high clouds increases.

In Chapter 3 of Grandey (2011), two other satellite datasets (Clouds and Earth's Radiant Energy System Single Scanner Footprint; and Advanced-Along Track Scanning Radiometer GlobAEROSOL $\tau$ data with Oxford-RAL Retrieval of Aerosol and Clouds $f_{\mathrm{c}}$ data) were also investigated. It was shown that positive $f_{\mathrm{c}}-\tau$ relationships also exist for these datasets, although the relationships are not as strong as in the Aqua-MODIS Collection 5 data.

As previously stated, the positive $f_{\mathrm{c}}-\tau$ relationships are not necessarily due to aerosol indirect effects on cloud. Cloud contamination of aerosol retrievals provides one potential explanation. In an attempt to investigate this error, the MODIS 


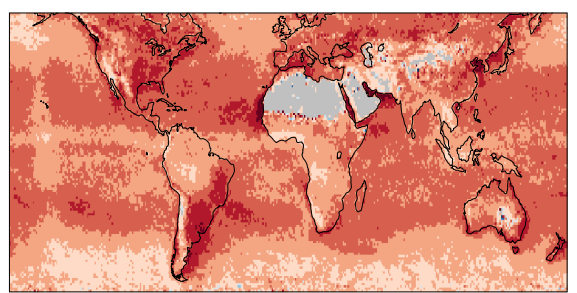

(a) Aqua-MODIS Coll. 5

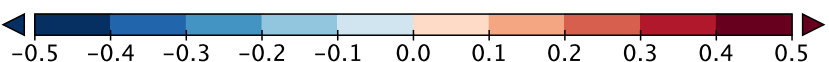

Fig. 1. Annual (all seasons) mean difference (high - low) in Aqua-MODIS Collection 5 cloud fraction $\left(f_{\mathrm{c}}\right)$ between low AquaMODIS aerosol optical depth ( $\tau<$ seasonal grid box median) conditions and high $\tau$ ( $\tau>$ seasonal grid box median) conditions. For more than $99 \%$ of the grid boxes with data, the mean difference is greater than the standard error in the mean difference for that grid box. The mean of the standard errors is 0.02 . Grey represents missing data.

$f_{\mathrm{c}}$ data are paired with MACC reanalysis-forecast $\tau$ data, a combination henceforth referred to as MODIS-MACC. The results of categorising according to low and high MACC $t+3 \mathrm{~h} \tau$ conditions are shown in Fig. 2a. Globally positive $f_{\mathrm{c}}-\tau$ relationships are again evident, although they are generally weaker than cases when MODIS $\tau$ is used. For a few small regions, notably part of the extratropical South Atlantic Ocean, weak negative $f_{\mathrm{c}}-\tau$ relationships are observed, indicated by pale blue. Over ocean, the global mean increase is now 0.13 ; over land, the increase is 0.15 .

Residual cloud contamination may remain in the MACC $\tau$ data due to the assimilation of satellite-retrieved $\tau$. This contamination should decrease for longer forecast times from assimilation, although model bias will increase as the forecast length increases. The MODIS-MACC $f_{\mathrm{c}}-\tau$ relationships for a longer MACC forecast of $t+24 \mathrm{~h}$ are shown in Fig. 2b. The relationships are generally weaker than for $t+3 \mathrm{~h}$, although the spatial patterns are similar. Negative $f_{\mathrm{c}}-\tau$ relationships are more evident in the tropics for the $t+24 \mathrm{~h} \tau$ data. Over ocean, the global mean increase is 0.09 ; over land, the increase is 0.12 . Assuming that the MACC $t+24 \mathrm{~h} \tau$ data do not contain model bias or residual cloud contamination, this suggests that cloud contamination may account for approximately one half of the observed global increase in $f_{\mathrm{c}}$ over ocean. However, it is difficult to disentangle the contributions from residual cloud contamination and introduced model bias.

It is worth noting that MODIS $\tau$ retrievals do not exist for completely cloudy grid boxes, whereas MACC $\tau$ data exist everywhere. Sampling differences such as these may be important (Sayer et al., 2010). When MACC $t+24 \mathrm{~h} \tau$ data are sampled according to Aqua-MODIS $\tau$ availability, fewer grid boxes show negative relationships. However, sampling choice does not have a large impact globally (Fig. S1a, b of the Supplement).

Results for the ECHAM5-HAM Sundqvist control simulation are shown in Fig. 2c. The spatial distribution of positive and negative relationships is remarkably similar between the Sundqvist control and the MODIS-MACC $t+$ $24 \mathrm{~h}$ results. The strong positive $f_{\mathrm{c}}-\tau$ relationships observed over the subtropical oceans, southern South America, North America, Asia and Australia are of similar size to those for the MODIS-MACC combinations. Further agreement is found in the extratropical ocean, where the relationships are weaker, with some weak negative relationships in the extratropical southern oceans. As observed in the MODISMACC $t+24 \mathrm{~h}$ data, negative $f_{\mathrm{c}}-\tau$ relationships are found over parts of the tropics, particularly South-East Asia, although these negative relationships are much stronger in the Sundqvist control data. These negative relationships, which occur primarily over the tropical ocean, greatly reduce the global mean increase in $f_{\mathrm{c}}$ to 0.03 over ocean. Over land, the global mean increase is 0.11 , comparable to the MODISMACC $t+24$ h results.

Seven possible mechanisms for $f_{\mathrm{c}}-\tau$ relationships were suggested at the beginning of this paper. The first of these, namely spatial gradient effects, has been avoided by conducting the analysis on small regions of $1^{\circ} \times 1^{\circ}$ or $1.875^{\circ} \times$ $1.875^{\circ}$. The second of these, namely cloud contamination of $\tau$, is difficult to remove from the satellite data, although an attempt has been made to investigate this error by using MACC $\tau$. Cloud contamination does not impact the ECHAM5-HAM model results. Four possible mechanisms remain for explaining the ECHAM5-HAM Sundqvist control results. Two of these would predict positive $f_{\mathrm{c}}-\tau$ relationships: the aerosol cloud lifetime effect and hygroscopic growth of aerosol in high relativity humidity conditions. One would predict negative $f_{\mathrm{c}}-\tau$ relationships: wet scavenging of aerosol by precipitation. The contributions of these three effects to the ECHAM5-HAM Sundqvist control results are now investigated. The two remaining possible mechanisms, whereby spurious $f_{\mathrm{c}}-\tau$ relationships are caused by other meteorological factors or cloud processing of aerosols, are not tested here.

First, the contribution of the cloud lifetime effect is investigated. The control simulation contains a representation of the cloud albedo and cloud lifetime effects, assuming the cloud lifetime effect can be represented through a modulation of autoconversion only. These aerosol indirect effects are not included in the NoAIE simulation. The difference in $f_{\mathrm{c}}$ between low and high $\tau$ conditions for the NoAIE simulation is shown in Fig. 2d. A slight weakening of positive $f_{\mathrm{c}}-\tau$ relationships occurs over many subtropical ocean areas, and the differences in the southern Indian Ocean become more negative. However, a slight strengthening of positive $f_{\mathrm{c}}-\tau$ relationships occurs over land for the NoAIE run, opposite of what would be expected from the conceptual cloud lifetime effect. These results suggest that the model-simulated 


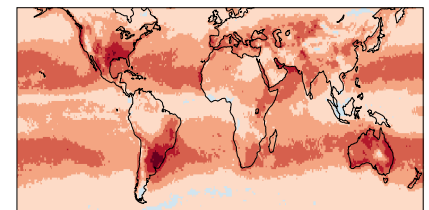

(a) MODIS-MACC $\mathrm{t}+3$ hour

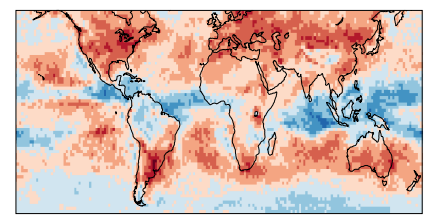

(d) Sundqvist NoAIE

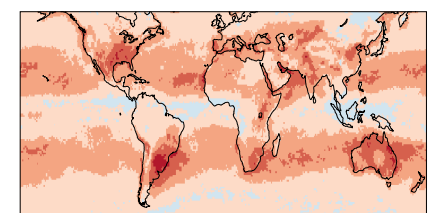

(b) MODIS-MACC $t+24$ hour

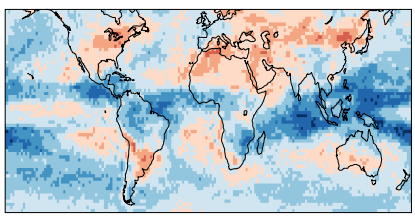

(e) Sundqvist Control Dry

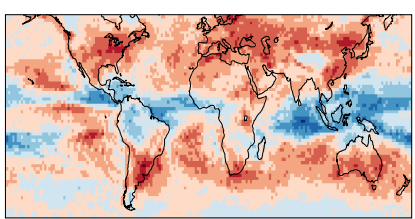

(c) Sundqvist Control

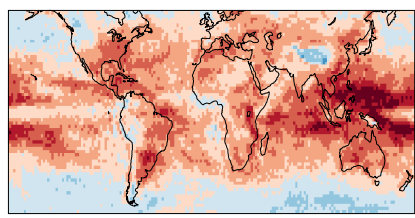

(f) Sundqvist NoConvScav

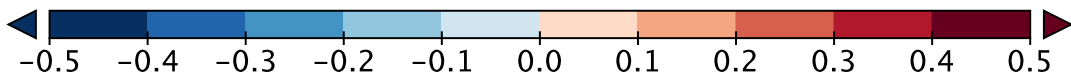

Fig. 2. Same as Fig. 1 , but for (a) Aqua-MODIS $f_{\mathrm{c}}$ with MACC $t+3 \tau$, (b) Aqua-MODIS $f_{\mathrm{c}}$ with MACC $t+24 \tau$, (c) ECHAM5-HAM Sundqvist control simulation $f_{\mathrm{c}}$ with $\tau$, (d) Sundqvist NoAIE $f_{\mathrm{c}}$ with $\tau$, (e) Sundqvist control $f_{\mathrm{c}}$ with dry $\tau$ and (f) Sundqvist NoConvScav $f_{\mathrm{c}}$ with $\tau$. The means of the standard errors are (a)-(c) 0.02 and (d)-(e) 0.03. Corresponding results for sampled MODIS-MACC and the ECHAM5-HAM Tompkins simulations are shown in Fig. S1 of the Supplement.

indirect effects are not the primary mechanism responsible for the positive $f_{\mathrm{c}}-\tau$ relationships observed in the control simulation. This is consistent with the findings of Lohmann et al. (2006) and Quaas et al. (2010).

Second, the contribution of relative humidity is investigated. In order to do this, dry $\tau$ from the control simulation is used instead of total $\tau$. Dry $\tau$ provides a surrogate for the $\mathrm{CCN}$ which would be activated at a given supersaturation but which is independent of relative humidity. Because $\tau$ is heavily dependent on aerosol size, dry $\tau$ is generally much lower than $\tau$ (Fig. S2a, b). The $f_{\mathrm{c}}$ difference between low and high dry $\tau$ conditions in the control run is shown in Fig. 2e. It can be clearly seen that using dry $\tau$ removes the majority of the positive $f_{\mathrm{c}}-\tau$ relationships over ocean. Many land areas retain positive $f_{\mathrm{c}}-\mathrm{dry} \tau$ relationships. However, these positive relationships are significantly weakened compared to when total $\tau$ is used. A global mean negative $f_{\mathrm{c}}-$ dry $\tau$ relationship is found over both ocean and land. These results demonstrate that relative humidity is the primary driver for the positive $f_{\mathrm{c}}-\tau$ relationships, in agreement with Quaas et al. (2010) and Chand et al. (2012).

Third, the contribution of wet scavenging is investigated. The negative $f_{\mathrm{c}}-\tau$ relationships in the control run are generally found in the tropics, where convective precipitation dominates, constituting $95 \%$ of the $20^{\circ} \mathrm{S}-20^{\circ} \mathrm{N}$ precipitation in the control simulation. It is these negative relationships which are of interest here, so wet scavenging by convective precipitation is switched off for the NoConvScav simulation, although the convective precipitation itself remains. Scavenging by stratiform cloud precipitation remains. Wet scavenging is the major removal mechanism for aerosol in ECHAM5-HAM. As a result, $\tau$ is generally much higher in the the NoConvScav simulation compared to the control simulation, particularly in the tropics (Fig. S2c). The lifetime of aerosols in ECHAM5-HAM is typically less than a week when scavenging is turned on (Stier et al., 2005). Switching off convective scavenging increases $\tau$ by a factor of approximately three, suggesting a lifetime of less than three weeks for the NoConvScav simulation. Therefore the three month spin-up should allow these concentrations to reach an equilibrium by the start of the year 2000 analysis period. Figure $2 \mathrm{f}$ shows the results for the NoConvScav simulation. Most of the negative $f_{\mathrm{c}}-\tau$ relationships found in the tropics of the control simulation are removed, becoming positive in the NoConvScav simulation. This demonstrates that wet scavenging by convective precipitation is the primary reason for the strong negative $f_{\mathrm{c}}-\tau$ relationships found in the tropics of the control simulation. Interestingly, the $f_{\mathrm{c}}-\tau$ relationships become more negative for many extratropical ocean areas in the NoConvScav simulation compared to the control simulation. This may be because wet scavenging by stratiform cloud precipitation may become a more significant aerosol removal mechanism in the NoConvScav run, leading to more negative relationships in regions where stratiform precipitation dominates.

Since $\tau$ cannot be retrieved in cloudy conditions, passive satellite radiometers such as MODIS may have poor sampling of negative $f_{\mathrm{c}}-\tau$ relationships arising due to scavenging. This may partly explain the absence of negative relationships in the Aqua-MODIS data, and also the reduction in the number of grid boxes with negative relationships when sampling is applied to the MODIS-MACC $t+24 \mathrm{~h}$ data. Although some negative relationships are observed for MODIS-MACC $t+24 \mathrm{~h}$, the MODIS-MACC combination 
may underestimate the negative relationships due to differences between modelled precipitation and real precipitation for a given location and day.

The results for simulations where the Tompkins stratiform cloud cover scheme is used are similar to those for the Sundqvist results described above (Fig. S1c-f in the Supplement). The results for two alternative methods of quantifying the $f_{\mathrm{c}}-\tau$ relationships, namely $\frac{\mathrm{d} f_{\mathrm{c}}}{\mathrm{d} \ln \tau}$ gradients and correlations, are shown in Figs. S3 and S4 in the Supplement. Similar conclusions can be reached using these figures, showing that the findings presented in this study appear to be insensitive to different methods of quantifying the $f_{\mathrm{c}}-\tau$ relationships.

In this paper, $\tau$ has been used, following the observational studies of Koren et al. (2005), Kaufman et al. (2005) and Yuan et al. (2011). However, it has been suggested that aerosol index (AI), the product of $\tau$ and the Ångström exponent, may provide a better measure of aerosol number burden than $\tau$ does (Nakajima et al., 2001). This is because the size of the aerosol particles is taken into account via the Ångström exponent. As a result, some cloud-aerosol interaction studies have used AI instead of $\tau$ (e.g. Penner et al., 2011). It is unclear whether the findings presented here for $f_{\mathrm{c}}-\tau$ relationships would also apply to $f_{\mathrm{c}}-\mathrm{AI}$ relationships. It is possible that AI may be less affected by relative humidity than $\tau$ is, due to the fact that $\mathrm{AI}$ is less sensitive to aerosol size.

\section{Conclusions}

Strong positive relationships between retrieved $f_{\mathrm{c}}$ and $\tau$ are observed in Aqua-MODIS satellite data. A global mean $f_{\mathrm{c}}$ increase of 0.20 between low and high $\tau$ conditions is found for both ocean and land.

Categorising the Aqua-MODIS $f_{\mathrm{c}}$ data according to MACC reanalysis-forecast $t+3 \mathrm{~h} \tau$ data results in a general weakening of the observed positive $f_{\mathrm{c}}-\tau$ relationships. The positive relationships are weakened further for a longer MACC forecast period of $t+24 \mathrm{~h}$. This provides some evidence to suggest that part of the positive $f_{\mathrm{c}}-\tau$ relationships observed in the MODIS data may be due to cloud contamination, although the weakening of the relationships may also be due to MACC model errors. Positive $f_{\mathrm{c}}-\tau$ relationships are still observed to dominate globally for the MODIS-MACC combinations, particularly in the subtropics. However, negative relationships emerge over parts of the tropics and extratropical southern oceans in the $t+24 \mathrm{~h}$ data.

The results of ECHAM5-HAM control simulations generally agree well with the MODIS-MACC results in the subtropics and extratropics. In agreement with the MODISMACC $t+24 \mathrm{~h}$ results, negative $f_{\mathrm{c}}-\tau$ relationships are found in parts of the tropics. However, these negative relationships are found to be much stronger in the ECHAM5-HAM control simulations. NoAIE simulations, in which simulated aerosol indirect effects have been switched off, demonstrate that the cloud lifetime effect is not the primary contributor to positive $f_{\mathrm{c}}-\tau$ relationships in ECHAM5-HAM. Rather, the positive relationships are primarily due to hygroscopic swelling of aerosols in high relative humidity conditions, demonstrated by using dry $\tau$ instead of total $\tau$. NoConvScav simulations, in which convective wet scavenging has been switched off, demonstrate that the negative $f_{\mathrm{c}}-\tau$ relationships in the tropics are primarily due to wet scavenging by convective precipitation. These results demonstrate the important contribution of wet scavenging to aerosol-cloud interactions.

Wet scavenging events are likely poorly sampled in retrieved satellite data, due to the absence of $\tau$ retrievals in cloudy conditions. This may partly explain why negative relationships are not observed in the Aqua-MODIS data. Similarly, this may also explain an absence of negative relationships between retrieved rain rate and $\tau$ (Koren et al., 2012). Quantifying the role of wet scavenging, and assessing GCM representations of this process, remains a challenge for future observational studies of aerosol-cloud-precipitation interactions.

It would be beneficial if the findings presented here were to be further analysed in future studies using different tools and methodologies. In particular, analysing $f_{\mathrm{c}}-\tau$ relationships for different cloud regimes may provide further insight. Such a regime-based approach has already been applied to the investigation of relationships between $\tau$ and cloud droplet number concentration (Gryspeerdt and Stier, 2012). Largescale synoptic conditions, such as those associated with extratropical cyclones, can also be considered (Grandey et al., 2013). It would also be beneficial to identify the reasons for $f_{\mathrm{c}}-\tau$ relationships in other global model datasets. The GCM results can be supplemented by cloud-resolving models, which are more accurate tools for the investigation of cloud-scale processes for specific regimes and geographical regions.

\section{Supplementary material related to this article is available online at: http://www.atmos-chem-phys.net/13/ 3177/2013/acp-13-3177-2013-supplement.pdf.}

\begin{abstract}
Acknowledgements. MODIS data were obtained from the Level 1 and Atmosphere Archive and Distribution System (LAADS). MACC data were obtained from the European Centre for MediumRange Weather Forecasts (ECMWF). This work was supported by a UK Natural Environment Research Council (NERC) DPhil studentship. The research leading to these results has received funding from the European Research Council under the European Union's Seventh Framework Programme (FP7/2007-2013)/ERC grant agreement no. FP7-280025. The authors would like to thank Jean-Jacques Morcrette, Angela Benedetti, Johannes Quaas, Rosalind West and two anonymous reviewers for helpful discussions and comments.
\end{abstract}

Edited by: J. H. Seinfeld 


\section{References}

Ackerman, A. S., Toon, O. B., Stevens, D. E., Heymsfield, A. J., Ramanathan, V. and Welton, E. J.: Reduction of tropical cloudiness by soot, Science, 288, 1042-1047, doi:10.1126/science.288.5468.1042, 2000.

Albrecht, B. A.: Aerosols, cloud microphysics, and fractional cloudiness, Science, 245, 1227-1230, 1989.

Andreae, M. O.: Correlation between cloud condensation nuclei concentration and aerosol optical thickness in remote and polluted regions, Atmos. Chem. Phys., 9, 543-556, doi:10.5194/acp-9-543-2009, 2009.

Bar-Or, R. Z., Koren, I., Altaratz, O., and Fredj, E.: Radiative properties of humidified aerosols in cloud environment, Atmos. Res., 118, 280-294, doi:10.1016/j.atmosres.2012.07.014, 2012.

Benedetti, A., Morcrette, J.-J., Boucher, O., Dethof, A., Engelen, R. J., Fisher, M., Flentje, H., Huneeus, N., Jones, L., Kaiser, J. W., Kinne, S., Mangold, A., Razinger, M., Simmons, A. J., and Suttie, M.: Aerosol analysis and forecast in the European Centre for Medium-Range Weather Forecasts Integrated Forecast System: 2. Data assimilation, J. Geophys. Res., 114, D13205, doi:10.1029/2008JD011115, 2009.

Chand, D., Wood, R., Ghan, S. J., Wang, M., Ovchinnikov, M., Rasch, J. P., Miller, S., Schichtel, B., and Moore, T.: Aerosol optical depth increase in partly cloudy conditions, J. Geophys. Res., 117, D17207, doi:10.1029/2012JD017894, 2012.

Engström, A. and Ekman, A. M. L.: Impact of meteorological factors on the correlation between aerosol optical depth and cloud fraction, Geophys. Res. Lett., 37, L18814, doi:10.1029/2010GL044361, 2010.

Forster, P., Ramaswamy, V., Artaxo, P., Berntsen, T., Betts, R., Fahey, W. D., Haywood, J., Lean, J., Lowe, D. C., Myhre, G., Nganga, J., Prinn, R., Raga, G., Schultz, M., and Van Dorland, R.: Changes in atmospheric constituents and in radiative forcing, in: Climate Change 2007: The Physical Science Basis, Contribution of Working Group 1 to the Fourth Assessment Report of the Intergovernmental Panel on Climate Change, Cambridge University Press, 2007.

Grandey, B. S.: Investigating aerosol-cloud interactions, $\mathrm{PhD}$ thesis, University of Oxford, UK, available at: http://ora.ox.ac.uk/ objects/uuid:8b48c02b-3d43-4b04-ae55-d9885960103d, 2011.

Grandey, B. S. and Stier, P.: A critical look at spatial scale choices in satellite-based aerosol indirect effect studies, Atmos. Chem. Phys., 10, 11459-11470, doi:10.5194/acp-10-11459-2010, 2010.

Grandey, B. S., Stier, P., Wagner, T. M., Grainger, R. G., and Hodges, K. I.: The effect of extratropical cyclones on satelliteretrieved aerosol properties over ocean, Geophys. Res. Lett., 38, L13805, doi:10.1029/2011GL047703, 2011.

Grandey, B. S., Stier, P., Grainger, R. G., and Wagner, T. M.: The contribution of extratropical cyclones to observed cloud-aerosol relationships, Atmos. Chem. Phys. Discuss., accepted, 2013.

Gryspeerdt, E. and Stier, P.: Regime-based analysis of aerosolcloud interactions, Geophys. Res. Lett., 39, L21802, doi:10.1029/2012GL053221, 2012.

Huang, J., Hsu, N. C., Tsay, S.-C., Jeong, M.-J., Holben, B. N., Berkoff, T. A., and Welton, E. J.: Susceptibility of aerosol optical thickness retrievals to thin cirrus contamination during the BASE-ASIA campaign, J. Geophys. Res., 116, D08214, doi:10.1029/2010JD014910, 2011.
Kaufman, Y. J., Koren, I., Remer, L. A., Rosenfeld, D., and Rudich, Y.: The effect of smoke, dust, and pollution aerosol on shallow cloud development over the Atlantic Ocean, P. Natl. Acad. Sci. USA, 102, 11207-11212, doi:10.1073/pnas.0505191102, 2005.

Koren, I., Kaufman, Y. J., Rosenfeld, D., Remer, L. A., and Rudich, Y.: Aerosol invigoration and restructuring of the Atlantic convective clouds, Geophys. Res. Lett., 32, L14828, doi:10.1029/2005GL023187, 2005.

Koren, I., Remer, L. A., Kaufman, Y. J., Rudich, Y., and Martins, J. V.: On the twilight zone between clouds and aerosols, Geophys. Res. Lett., 34, L08805, doi:10.1029/2007GL029253, 2007.

Koren, I., Feingold, G., and Remer, L. A.: The invigoration of deep convective clouds over the Atlantic: aerosol effect, meteorology or retrieval artifact?, Atmos. Chem. Phys., 10, 8855-8872, doi:10.5194/acp-10-8855-2010, 2010.

Koren, I., Altaratz, O., Remer, L. A., Feingold, G., Martins, J. V., and Heiblum, R. H.: Aerosol-induced intensification of rain from the tropics to the mid-latitudes, Nat. Geosci., 5, 118-122, doi:10.1038/NGEO1364, 2012.

Lohmann, U. and Feichter, J.: Global indirect aerosol effects: a review, Atmos. Chem. Phys., 5, 715-737, doi:10.5194/acp-5-7152005, 2005.

Lohmann, U., Koren, I., and Kaufman, Y. J.: Disentangling the role of microphysical and dynamical effects in determining cloud properties over the Atlantic, Geophys. Res. Lett., 33, L09802, doi:10.1029/2005GL024625, 2006.

Lohmann, U., Stier, P., Hoose, C., Ferrachat, S., Kloster, S., Roeckner, E., and Zhang, J.: Cloud microphysics and aerosol indirect effects in the global climate model ECHAM5-HAM, Atmos. Chem. Phys., 7, 3425-3446, doi:10.5194/acp-7-3425-2007, 2007.

Morcrette, J.-J., Boucher, O., Jones, L., Salmond, D., Bechtold, P., Beljaars, A., Benedetti, A., Bonet, A., Kaiser, J. W., Razinger, M., Schulz, M., Serrar, S., Simmons, A. J., Sofiev, M., Suttie, M., Tompkins, A. M., and Untch, A.: Aerosol analysis and forecast in the European Centre for Medium-Range Weather Forecasts integrated forecast system: forward modeling, J. Geophys. Res., 114, D06206, doi:10.1029/2008JD011235, 2009.

Morcrette, J.-J., Benedetti, A., Jones, L., Kaiser, J. W., Razinger, M., and Suttie, M.: Prognostic aerosols in the ECMWF IFS: MACC vs. GEMS aerosols, ECMWF Tech. Memo. 659, available at: http://www.ecmwf.int/publications/ library/ecpublications/\%5Fpdf/tm/601-700/tm659.pdf, last access: 2012-11-28, European Centre for Medium-Range Weather Forecasts, Reading, UK, 32 pp., 2011.

Nakajima, T., Higurashi, A., Kawamoto, K., and Penner, J. E.: A possible correlation between satellite-derived cloud and aerosol microphysical parameters, Geophys. Res. Lett., 28, 1171-1174, doi:10.1029/2000GL012186, 2001.

Penner, J. E., Xu, L., and Wang, M.: Satellite methods underestimate indirect climate forcing by aerosols, P. Natl. Acad. Sci. USA, 108, 13404-13408, doi:10.1073/pnas.1018526108, 2011.

Platnick, S., King, M. D., Ackerman, S. A., Menzel, W. P., Baum, B. A., Riedi, J. C., and Frey, R. A.: The MODIS cloud products: algorithms and examples from Terra, IEEET. Geosci. Remote, 41, 459-473, doi:10.1109/TGRS.2002.808301, 2003. 
Pruppacher, H. R. and Jaenicke, R.: The processing of water vapor and aerosols by atmospheric clouds, a global estimate, Atmos. Res., 38, 283-295, 1995.

Quaas, J., Ming, Y., Menon, S., Takemura, T., Wang, M., Penner, J. E., Gettelman, A., Lohmann, U., Bellouin, N., Boucher, O., Sayer, A. M., Thomas, G. E., McComiskey, A., Feingold, G., Hoose, C., Kristjánsson, J. E., Liu, X., Balkanski, Y., Donner, L. J., Ginoux, P. A., Stier, P., Grandey, B., Feichter, J., Sednev, I., Bauer, S. E., Koch, D., Grainger, R. G., Kirkevåg, A., Iversen, T., Seland, Ø., Easter, R., Ghan, S. J., Rasch, P. J., Morrison, H., Lamarque, J.-F., Iacono, M. J., Kinne, S., and Schulz, M.: Aerosol indirect effects - general circulation model intercomparison and evaluation with satellite data, Atmos. Chem. Phys., 9, 8697-8717, doi:10.5194/acp-98697-2009, 2009.

Quaas, J., Stevens, B., Stier, P., and Lohmann, U.: Interpreting the cloud cover - aerosol optical depth relationship found in satellite data using a general circulation model, Atmos. Chem. Phys., 10, 6129-6135, doi:10.5194/acp-10-6129-2010, 2010.

Remer, L. A., Kaufman, Y. J., Tanré, D., Mattoo, S., Chu, D. A., Martins, J. V., Li, R.-R., Ichoku, C., Levy, R. C., Kleidman, R. G., Eck, T. F., Vermote, E., and Holben, B. N.: The MODIS aerosol algorithm, products, and validation, J. Atmos. Sci., 62, 947-973, doi:10.1175/JAS3385.1, 2005.

Sayer, A. M., Thomas, G. E., Palmer, P. I., and Grainger, R. G.: Some implications of sampling choices on comparisons between satellite and model aerosol optical depth fields, Atmos. Chem. Phys., 10, 10705-10716, doi:10.5194/acp-10-10705-2010, 2010.

Stier, P., Feichter, J., Kinne, S., Kloster, S., Vignati, E., Wilson, J., Ganzeveld, L., Tegen, I., Werner, M., Balkanski, Y., Schulz, M., Boucher, O., Minikin, A., and Petzold, A.: The aerosol-climate model ECHAM5-HAM, Atmos. Chem. Phys., 5, 1125-1156, doi:10.5194/acp-5-1125-2005, 2005.
Stier, P., Grandey, B. S., West, R., Lohmann, U., Quaas, J., and Seinfeld, J.: Observational constraints on mechanistic aerosol-cloud coupling in the microphysical aerosol-climate Model ECHAMHAM, in preparation, 2013.

Sundqvist, H., Berge, E., and Kristjánsson, J. E.: Condensation and cloud parameterization studies with a mesoscale numerical weather prediction model, Mon. Weather Rev., 117, 1641-1657, doi:10.1175/1520-0493(1989)117<1641:CACPSW > 2.0.CO;2, 1989.

Tompkins, A. M.: A prognostic parameterization for the subgrid-scale variability of water vapor and clouds in large-scale models and its use to diagnose cloud cover, J. Atmos. Sci., 59, 1917-1942, doi:10.1175/15200469(2002)059<1917:APPFTS>2.0.CO;2, 2002.

Várnai, T. and Marshak, A.: MODIS observations of enhanced clear sky reflectance near clouds, Geophys. Res. Lett., 36, L06807, doi:10.1029/2008GL037089, 2009.

Yuan, T., Remer, L. A., and Yu, H.: Microphysical, macrophysical and radiative signatures of volcanic aerosols in trade wind cumulus observed by the A-Train, Atmos. Chem. Phys., 11, 71197132, doi:10.5194/acp-11-7119-2011, 2011.

Zhang, K., O’Donnell, D., Kazil, J., Stier, P., Kinne, S., Lohmann, U., Ferrachat, S., Croft, B., Quaas, J., Wan, H., Rast, S., and Feichter, J.: The global aerosol-climate model ECHAM-HAM, version 2: sensitivity to improvements in process representations, Atmos. Chem. Phys., 12, 8911-8949, doi:10.5194/acp-12-8911-2012, 2012. 